\title{
CONDUCTIVITY OF THE JUNCTION: D-WAVE PAIRING SUPERCONDUCTIVE GRAPHENE - NORMAL GRAPHENE WITH DIFFERENT FERMI VELOCITY
}

\author{
A. Korol, N. Medvid, V. Vyshniak, S. Litvynchuk \\ National University of Food Technologies
}

\begin{tabular}{l}
\multicolumn{1}{c}{ Key words: } \\
Graphene \\
Superconductivity \\
Fermi velocity \\
Conductivity \\
\hline \multicolumn{1}{c}{ Article history: } \\
Received 14.11.2018 \\
Received in revised form \\
30.11.2018 \\
Accepted 17.12.2018 \\
\hline
\end{tabular}

Corresponding author:

A. Korol

E-mail:

korolam@ukr.net

\begin{abstract}
The conductivity of the normal graphene - d-wave superconductive graphene junction is calculated within the framework of the Blonder-Tinkham-Klapwijk formalism [1]. The eigenfunctions, the Andreev and the normal reflection rates are evaluated by solving the Dirac-Bogoliubov-de Gennes equations. The Fermi velocity is believed to be different in the normal and in the superconductive regions [2]. We considered the case of the gapped graphene.

Along with the s-wave pairing considered in the papers [16-17] there may take place the unconventional order parameters such as $d$-wave, $p$-wave and even $f$-wave superconductivity [17]. It is clear that the transport in the structures which are described by the non-isotropic pairing symmetry may essentially differ from that of s-pairing. It is demonstrated in this work that for the d-wave superconductivity the characteristics of the considered junction are sensitive to the value of $z=v_{n} / v_{\mathrm{s}}$, where vn, vs are the Fermi velocities in the normal and the superconductive graphene respectively. This conclusion refers to the Andreev reflection as well as to the normal one. The first of them is shown to be the dominant process for the formation of the conductivity. These results are true for an arbitrary value of the orientational angle of the $d$-waves. The dependence of the conductivity on the external electrostatic potential as well as on the Fermi energy is also analyzed. The conductivity $G(E)$ is calculated taking into account the fact that the external potential $U$ is applied to the superconductive part of the given structure.

A characteristic feature of the $G(E)$ dependence is the presence of a peak at the energy point which depends on the value of the rotational angle. The value of the maximum (peak) value of $G(E)$ curve steepness essentially depends on the value of the Fermi velocity $v_{F}$. The dependence of the conductivity on the potential $U$ as well as on the Fermi level $E F$ is analyzed for different values of the rotational angle. The obtained results may be useful for applications in the graphene-based electronics.
\end{abstract}

DOI: $10.24263 / 2225-2924-2018-24-6-18$ 


\title{
ПРОВІДНІСТЬ КОНТАКТУ: НАДПРОВІДНИЙ ГРАФЕН 13 D-ХВИЛЬОВИМ СПАРЮВАННЯМ - НОРМАЛЬНИЙ ГРАФЕН ІЗ РІЗНИМИ ШВИДКОСТЯМИ ФЕРМІ
}

\author{
А.М. Король, Н.В. Медвідь, В.В. Вишняк, С.І. Літвинчук \\ Національний університет харчових технологій
}

У рамках формалізму Блондера-Тинкхема-Клапвійка розраховується провідність контакту: нормальний графен - $d$-хвильовий надпровідний графен. Власні функиії, коефіцієнти андріївського та нормального відбивання обчислюються за допомогою розв'язування рівняння Дірака-Боголюбова-де Жена. Вважається, щз швидкості Фермі набувають різних значень в нормальній $i$ надпровідній областях. Розглядається випадок щуільового графена.

Крім s-хвильового спарювання, яке розглядалось у [16; 17], можливими $\epsilon$ також неконвенційні параметри порядку, такі як $d$-хвильова, р-хвильова $i$ навіть $f$-хвильова надпровідності. У статті показано, щзо характеристики контакту для $d$-хвильової надпровідності $\epsilon$ вельми чутливими до значення $z=v_{n} / v_{s}$ де, $v_{n}$ mа $v_{s}$ - швидкості Фермі в нормальній і надпровідній областях відповідно. Цей висновок стосується як андріївського, так і нормального відбивання. Показано, щзо перше з них є домінуючим процесом у формуванні провідності. Одержані результати є правильними для довільного значення орієнтаційного кута $d$-хвиль. Також розраховано $і$ проаналізовано залежність електропровідності від зовнішнього електростатичного потенціалу та від енергії Фермі. Провідність $G(E)$ розраховано з урахуванням того факту, щзо зовнішній електричний потенціал прикладено до надпровідної частини контакту, шзо розглядається.

Характерною рисою залежності провідності від енергї Фермі квазіелектронів $G(E)$ є наявність максимальних значень (піків) у залежності $G(E)$. Крім того, крутизна кривих $G(E)$ істотно залежить від значення швидкості Фермі $v_{F}$. Проаналізовано залежність провідності від зовнішнього електростатичного потенціалу, а також від енергї Фермі для різних значень ротаизійного кута. Одержані результати можуть бути корисними в пристроях електроніки на основі графену.

Ключові слова: графен, надпровідність, ивидкість Фермі, провідність.

Introduction. In recent years, much attention has been paid to the study of graphene and various graphene-based structures. This is due to non-trivial properties of graphene, such as a linear dispersion law for the quasi-particles, whose behavior at low energies is described by an equation similar to the DiracWeyl one, unusual quantum Hall effect, the property of chirality, the Klein tunneling, high mobility, ballistic transport etc. [1, 2]. It should also be borne in mind that graphene is a promising material in modern electronics in terms of replacing the silicon technology, the development of which has reached its limit, for the graphene one. One of the priority directions is to study the various possibilities of controlling the energy spectrum of the graphene-based structures. 
Recently one new method for this purpose was proposed. The Fermi velocity of charge carriers in these structures is made to vary in space by some special techniques, e.g. by placing a grounded metal plane close to graphene sheet (which makes electron-electron interactions weaker and thereby modifies the Fermi velocity), by the appropriate doping, imprinting on graphene a lateral superlattice with gexagonal symmetry. The electron-wave propagation in the graphene-based structures with the tunable Fermi velocity was investigated in [3-11] including the effect of the magnetic and the electric field. At the same time the pristine graphene can also be induced by the external forces to become the superconducting material, for example, superconductivity can be induced in a graphene layer in the presence of a superconducting electrode near it due to the proximity effect. That's why a lot of works were devoted to exploring of the properties of such structures as the graphene - superconductive graphene, graphene - insulator-superconductive graphene, graphene-based Josephson junctions. However, the effect of tuning of the Fermi velocity on the characteristics of these contacts has not been investigated so far. Motivated by these circumstances, in the previous article [15] we have considered the normal graphene-superconductive graphene (NG-SG) contact with various values of the Fermi velocity and analyze its transmission properties. At the same time it is proper to note that along with the s-wave pairing considered in [16 - 17] there may take place the unconventional order parameters such as dwave, p-wave and even f-wave superconductivity [17]. It is clear that the transport in the structures which are described by the non-isotropic pairing symmetry may essentially differ from that of s-pairing. That's why, in this paper, we analyze the transmission properties of the normal graphene- $d$-wave superconductor junction with the different Fermi values in the superconductor.

Model and formulae. Let the normal and the superconductive parts of the junction studied are placed along the $0 x$ axis so that their interface locates at a point $x=0$. We modeled the $d$-wave pairing with the help of the so called $d_{x^{2}-y^{2}}$ model so that the superconducting order parameter is of the form

$$
\Delta_{s}=\Theta(x) e^{i \varphi} \Delta \cos \left(2_{S}-2 \alpha\right) .
$$

Where $\Theta(x)$ is the Heaviside unit step function, $\varphi$ is the superconductive phase, $\Theta_{s}$. angle of incidence of the quasiparticles, $\alpha$ the rotational angle. The eigenfunctions which describe the quasiparticle in this system are subjected to the DiracBogolyubov-de Jennes equation

$$
\left[\begin{array}{cc}
H-U(x) & \Delta(x) \\
\Delta^{*}(x) & -H+U(x)
\end{array}\right] \Psi(x)=E \Psi(x) .
$$

Where $H=-i h v_{F}\left(\sigma_{x} \partial_{x}+\sigma_{y} \partial_{y}\right)$ is the Dirac Hamiltonian, $U$ the external electrostatic potential applied to the superconducting region, $v_{F}$ the Fermi velocity, $\sigma_{x}$, $\sigma_{y}$ Pauli matrices for the pseudospin. The solution of the equation (2) is the fourcomponent electron and hole spinors which are of the following form: 
- in NG region

$$
\Psi_{N}(x)=\left(\begin{array}{c}
1 \\
e^{i_{N}} \\
0 \\
0
\end{array}\right) e^{i k_{N e} x}+r_{n}\left(\begin{array}{c}
1 \\
-e^{-i_{N}} \\
0 \\
0
\end{array}\right) e^{-i k_{N e} x}+r_{a}\left(\begin{array}{c}
0 \\
0 \\
1 \\
e^{i_{N}}
\end{array}\right) e^{-i k_{N h} x}
$$

- in SG region

$$
\begin{aligned}
& \Psi_{S}(x)=t\left(\begin{array}{c}
1 \\
e^{i_{S}} \\
e^{-i \beta} e^{-i \varphi} \\
e^{i_{S}} e^{-i \beta} e^{-i \varphi}
\end{array}\right) e^{i k_{S} x-k x}++t^{\prime}\left(\begin{array}{c}
1 \\
-e^{-i_{S}} \\
e^{i \beta} e^{-i \varphi} \\
-e^{-i_{S}} e^{i \beta} e^{-i \varphi}
\end{array}\right) e^{-i k_{S} x-k x} \\
& k_{N e(h)}=\frac{\cos \Theta_{N e(h)}}{v_{F N}} \sqrt{\left[E_{F N}+(-) E\right]^{2}-\Delta_{N}^{2}} ; \\
& k_{S}=\left(E_{F N}+U\right) \frac{\cos \Theta_{S}}{v_{F S}} ; \\
& k^{-1}=\frac{v_{F S}^{2} k_{S}}{\left(U+E_{F N}\right) \Delta_{S} \sin \beta} ; \\
& \beta=\cos ^{-1}\left(\frac{E}{\Delta_{S}}\right) \text { if }|E|<\Delta_{S} ; \\
& \beta=-i \cosh \left(\frac{E}{\Delta_{S}}\right) \text { if }|E|>\Delta_{S} .
\end{aligned}
$$

Units $\hbar=v_{0}=1$ are adopted, $v_{0}$ being the Fermi velocity in the pristine graphene.

The coefficients in $(3,4)$ can be found by applying the following appropriate boundary conditions on the wavefunctions:

$$
\sqrt{v_{F N}} \Psi_{N}(x=0)=\sqrt{v_{F S}} \Psi_{S}(x=0) \text {. }
$$

As a result we obtain for the coefficients of the Andreev and normal reflections respectively:

$$
\begin{gathered}
r_{a}\left(E, \Theta_{N}, E_{F N}, U\right)=\frac{v(E) u(E) e^{-i \varphi} A_{5}\left(\Theta_{N}, E_{F N}, U\right) A_{6}\left(\Theta_{N}, E_{F N}, U\right)}{B\left(E, \Theta_{N}, E_{F N}, U\right)} \\
r_{n}\left(E, \Theta_{N}, E_{F N}, U\right)==A_{7}\left(\Theta_{N}, E_{F N}, U\right) \\
{\left[\frac{A_{7}\left(\Theta_{N}, E_{F N}, U\right) u(E)^{2}+A_{8}\left(\Theta_{N}, E_{F N}, U\right) v(E)^{2}}{B\left(E, \Theta_{N}, E_{F N}, U\right)}\right]-1}
\end{gathered}
$$


where we account for the condition

$$
E_{F N}, \Delta_{N} \gg E, \Omega
$$

and we use the following significations:

$$
\begin{aligned}
& \Omega=\sqrt{E^{2}-\left|\Delta \cos \left(2_{S}-2 \alpha\right)\right|^{2}} \\
& u(E)=\sqrt{0,5\left(1+\frac{\Omega(E)}{E}\right)} v(E)=\sqrt{0,5\left(1-\frac{\Omega(E)}{E}\right)} \\
& A_{N}\left(\Theta_{N}, E_{F N}, U\right)=\frac{E_{F N}-\Delta_{N}}{v_{F N} k_{N}\left(\Theta_{N}, E_{F N}\right)} e^{i \Theta_{N}} \\
& A_{N_{-}}\left(\Theta_{N}, E_{F N}, U\right)=\frac{E_{F N}-\Delta_{N}}{v_{F N} k_{N}\left(\Theta_{N}, E_{F N}, U\right)} e^{-i \Theta_{N}} \\
& A_{S}\left(\Theta_{N}, E_{F N}, U\right)=\frac{E_{F N}+U-\Delta_{N}}{v_{F S} k_{S}\left(\Theta_{N}, E_{F N}, U\right)} e^{i \Theta_{S}} \\
& A_{S_{-}}\left(\Theta_{N}, E_{F N}, U\right)=\frac{E_{F N}+U-\Delta_{N}}{v_{F S} k_{S}\left(\Theta_{N}, E_{F N}, U\right)} e^{-i \Theta_{S}} \\
& A_{1}\left(\Theta_{N}, E_{F N}, U\right)=A_{N_{-}}\left(\Theta_{N}, E_{F N}, U\right)+A_{S}\left(\Theta_{N}, E_{F N}, U\right) \\
& A_{2}\left(\Theta_{N}, E_{F N}, U\right)=A_{N}\left(\Theta_{N}, E_{F N}, U\right)+A_{S_{-}}\left(\Theta_{N}, E_{F N}, U\right) \\
& A_{3}\left(\Theta_{N}, E_{F N}, U\right)=A_{N_{-}}\left(\Theta_{N}, E_{F N}, U\right)-A_{S_{-}}\left(\Theta_{N}, E_{F N}, U\right) \\
& A_{4}\left(\Theta_{N}, E_{F N}, U\right)=A_{N}\left(\Theta_{N}, E_{F N}, U\right)-A_{S}\left(\Theta_{N}, E_{F N}, U\right) \\
& A_{5}\left(\Theta_{N}, E_{F N}, U\right)=A_{N_{-}}\left(\Theta_{N}, E_{F N}, U\right)+A_{N}\left(\Theta_{N}, E_{F N}, U\right) \\
& A_{6}\left(\Theta_{N}, E_{F N}, U\right)=A_{S}\left(\Theta_{N}, E_{F N}, U\right)+A_{S_{-}}\left(\Theta_{N}, E_{F N}, U\right) \\
& A_{7}\left(\Theta_{N}, E_{F N}, U\right)=A_{N_{-}}\left(\Theta_{N}, E_{F N}, U\right)+A_{N}\left(\Theta_{N}, E_{F N}, U\right) \\
& A_{8}\left(\Theta_{N}, E_{F N}, U\right)=A_{S}\left(\Theta_{N}, E_{F N}, U\right)-A_{N}\left(\Theta_{N}, E_{F N}, U\right) \\
& B\left(E, \Theta_{N}, E_{F N}, U\right)=u(E)^{2} A_{1}\left(\Theta_{N}, E_{F N}, U\right) \times \\
& \times A_{2}\left(\Theta_{N}, E_{F N}, U\right)-v(E)^{2} A_{3}\left(\Theta_{N}, E_{F N}, U\right) A_{4}\left(\Theta_{N}, E_{F N}, U\right) \\
& k_{N}\left(\Theta_{N}, E_{F N}\right)=\cos \left(\Theta_{N}\right) \sqrt{E_{F N}^{2}-\Delta_{N}^{2}} \frac{1}{\sqrt{v_{F N} v_{F S}}} \\
& k_{s}=\frac{1}{\sqrt{v_{F M} v_{F S}}} \sqrt{\left(E_{F}+U+\Omega\right)^{2}-\Delta_{N}}
\end{aligned}
$$


Angles of incidence of the quasiparticle wave on the normal and the superconductive regions of the junction considered are associated by the following condition

$$
k_{N} \sin \Theta_{N}=k_{S} \sin \Theta_{S}
$$

The conductivity $G$ of the junction investigated can be found due to known Blonder-Tinkham-Klapvijk formalism [12] which expresses $G$ in terms of $r_{a}$ and $r_{n}$ :

$$
\begin{gathered}
G\left(E, E_{F N}, U\right)=G_{0} \int_{0}^{\frac{\pi}{2}}\left[1+\left|r_{a}\left(E, \Theta_{N}, E_{F N}, U\right)\right|^{2}-\right. \\
\left.-\left|r_{n}\left(E, \Theta_{N}, E_{F N}, U\right)\right|^{2}\right] \cos \left(\Theta_{N}\right) d \Theta_{N}
\end{gathered}
$$

where $G_{0}$ is the ballistic conductivity of the normal graphene [14]. The equation (9) yields the conductivity of the structure under consideration for arbitrary parameter values.

Results and Discussion. We put the angle of incidence of the quasiparticle wave on the normal region to be equal to $\pi / 6$ throughout the text, the superconductive parameter $\Delta_{s}=0.0025$. First of all, we must note that the conductivity of this system $G^{*}$ reveals a complicated dependence on its parameters and the results of calculation of $G^{*}$ essentially depends on the interplay between the parameters such as the Fermi velocity in the normal and the superconducting regions (ratio $v_{F N} / v_{F S}$ ), the magnitude of a gap in the normal area $\Delta_{N}$, an external electrostatic potential $U$, the Fermi energy $E_{F}$.

Fig. 1 shows the dependence of the normal, the Andreev reflection, and also of the normalized (dimensionless) conductivity $G^{*}=G / G_{0}$ on the dimensionless energy of quasiparticles $E^{\prime}=E / \Delta_{S}$ in the case in which a normal part of the considered contact is the gapped graphene $\left(\Delta_{N}=1\right)$, the value of the rotational angle $\alpha$ is equal to $\pi / 6$

Since the qualitative behavior of the dependencies on energy for both the normal and the Andreev reflections are similar for all of the following figures we present further, starting from Fig. 2, only the dependence on energy for the conductivity of the system examined. There is a significant functional dependence of conductivity on the potential $U$, as well as on the Fermi level $E_{F}$. Because of this, in subsequent figures, we present the results of our calculations for two different values of $U$, namely $U_{1}=0$ and $U_{2}=100$. (Note that the conductivity of the system which includes the gapless graphene is independent of variables $U$ and $\left.E_{F}\right)$. It is seen from Fig. 1 that the functions $r_{a}(E)$ and $r_{n}(E)$, i.e. the rates of the Andreev and the normal reflection respectively have the peak-like extremes not at the energy point equal to the width of the superconducting gap $E=\Delta_{s}$, as it is for the case of the s-wave symmetry, but there is a substantial shift of this peak to 
lesser excitation energies due to the non-zero value of $\alpha$. It is true for arbitrary values of the potential $U$. However, the behavior of the Andreev and the normal reflection rates has the opposite character, namely the function $r_{a}(E)$ increases with energy $E$ from zero and reaches a maximum; instead the function $r_{n}(E)$ decreases with $E$ increasing, reaches a minimum value at the same energy point, and then grows. The value of conductivity $G^{*}(E)$ is mainly determined by the Andreev reflection process and the shape of the corresponding curve is similar to that of the function $r_{a}(E)$. We would like to emphasize here two important facts: 1) conductivity depends on the potential $U$ (unlike for the case where $\Delta_{N}=0, v_{F S}=1 ; 2$ ) increasing in potential $U$ leads to higher values of the conductivity unlike for the case of identical values Fermi velocity in $N$ and $S$ contact regions $\left(v_{F S}=v_{F N}=1, \Delta_{N} \neq 0\right)$. This behavior is due to the process of the Andreev reflection. Note also that the conductance increases with decreasing of the Fermi velocity in the superconducting region $v_{F S}$.
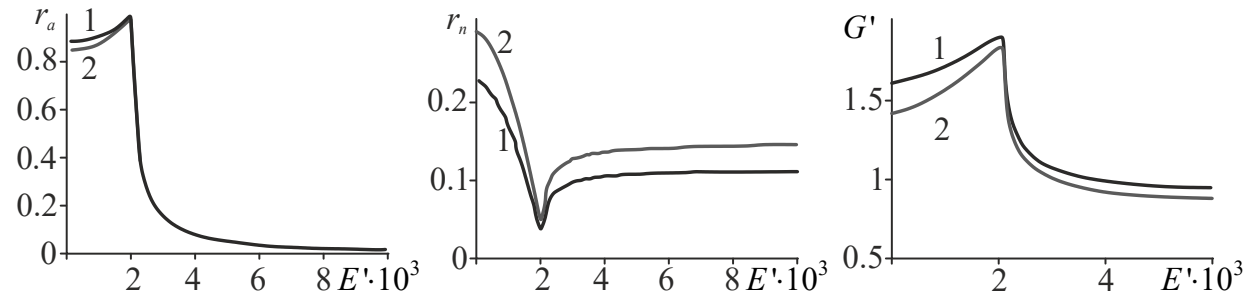

Fig. 1. Plots of $r_{a}\left(E^{\prime}\right), r_{n}\left(E^{\prime}\right), G^{*}\left(E^{\prime}\right)$ dependencies for the gapped normal region with the values of $\Delta_{N}=1, v_{F S}=1.5, \alpha=\pi / 6$. Curves 1,2 refer to values of $U=0,100$ respectively, $E_{F}=10$

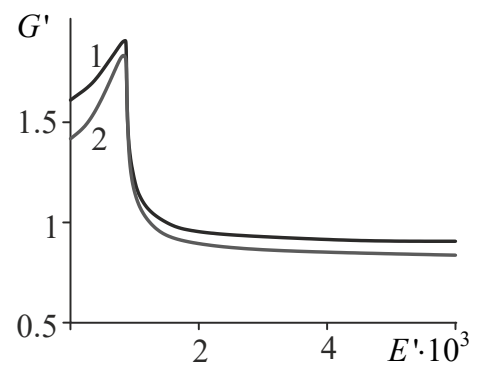

Fig. 2. The dependence of the conductivity on energy for $\alpha=\pi / 4, \Delta_{N}=1, v_{F S}=1.5$.

Curves 1, 2 refer to values of $U=0,100$ respectively, $E_{F}=10$

Fig. 2 presents the conductivity as a function of energy for the value of $\alpha$ which is equal to $\pi / 4$. Here the shift of the maximum peak is essentially larger than for the case of $\alpha=\pi / 6$ : hence the shift of the observed curves is very sensitive to values of the rotational angle in the $\mathrm{d}$-wave pairing. 


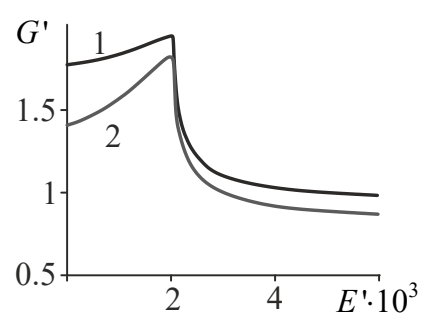

a

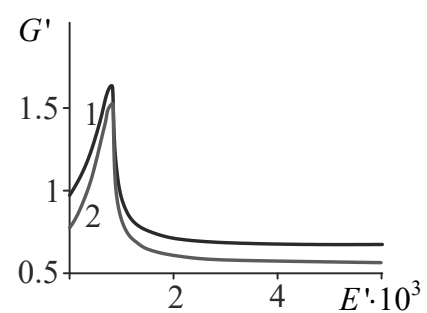

$\mathrm{b}$

Fig. 3a, $b$ The dependence of the conductivity on energy for the following values of the difference between the Fermi velocities in the normal and the superconductor areas:

$v_{F S}=1.2, \alpha=\pi / 6$ for Fig. 3a, and $v_{F S}=2, \alpha=\pi / 4$ for Fig. 3b. Curves 1, 2 refer to values of $U=0,100$ respectively, $E_{F}=10$

Fig. 3, presents the $G$ vs $E$ function for the following values of the difference between the Fermi velocities in the normal and the superconductor areas: $v_{F S}=1.2$, $\alpha=\pi / 6$ for Fig. 3a, and $v_{F S}=2, \alpha=\pi / 4$ for Fig. $3 \mathrm{~b}$.

We see from the Fig(s) 1-3 that the larger is the difference between the Fermi velocities in the normal and the superconductor areas, the more substantial effect on the conductivity we observe. For all the cases considered in which $v_{F S} \neq v_{F N}$, the magnitude of conductivity has a peak-like maximum at a point that depends on the value of $\alpha$; the maximum value of $G^{*}$ grows with $v_{F S}$ decreasing independently on $\alpha$ (if $v_{F S}>v_{F N}$ ).

In Fig. 4, the function $G(E)$ is plotted for the case of bigger gap in the normal region $\Delta_{N}=2$. For larger values of $\Delta_{N}$, there is an interesting result: the conductivity reveals the non-monotonic dependence on the Fermi velocity values in the superconductors region $v_{F S}$. In this case, contrary for the case of smaller values $\Delta_{N}$ the conductivity increases with increasing $v_{F S}$, then reaches its maximum at the value $v_{F S}$ which is approximately the same for different values of $\alpha$, then lessens; the location of the maximum essentially depends on $\alpha$.

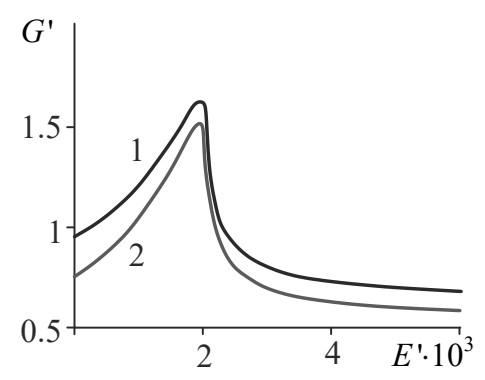

Fig. 4. The dependence of the conductivity on energy for the case of bigger gap in the normal region $\Delta_{N}=2 ; \alpha=\pi / 6, v_{F S}=1.5$. Curves 1,2 refer to values of $U=0,100$ respectively, $E_{F}=10$ 
Fig. 5 illustrates the dependence of the conductivity on energy for the Fermi level $E_{F, \text {, }}$ equal to 50. Comparing this figure with the previous ones we see that the function $G(E)$ depends substantially on $E_{\mathrm{F}}$ and it is true for an arbitrary value of $\alpha$. Decreasing in $E_{F}$ leads to the increased conductivity and not to its decreasing as for the case $v_{F S}=1, \Delta_{N} \neq 0$. The conductivity becomes practically independent on $U$ for sufficiently large values of $E_{F}$ (see Fig. 5).

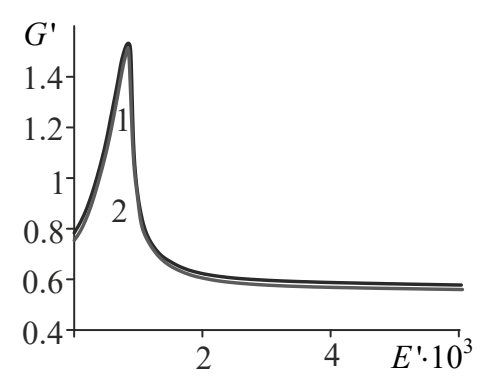

Fig. 5. The dependence of the conductivity on energy for the case of large value of $E_{F}=50$;

$v_{F S}=1.5, \alpha=\pi / 6$. Curves 1,2 refer to values of $U=0,100$ respectively

Considering the case of the junction studied with the gapless normal graphene we must note the following. Independently of values of $\alpha$ the conductivity does not depend on energy in the region where $E<\Delta_{S}$ - as for the case of s-pairing. The larger is the difference between the Fermi velocities in the normal and the superconductor areas, the more substantial effect on the conductivity we observe for each value of $\alpha$. As for the case of the gapped normal graphene, for all the cases considered in which $v_{F S} \neq v_{F N}$, the magnitude of conductivity has a peak-like maximum at a point $E=\Delta_{S}$; the maximum value of $G^{*}$ grows with $v_{F S}$ decreasing (if $v_{F S}>v_{F N}$ ). The function $G(E)$ is independent on the external potential $U$ for the case $\Delta_{N}=0, v_{F S} \neq 1$.

\section{Conclusions}

The following nanoscale structure is considered: the d-wave pairing superconducting graphene in contact with the normal graphene. It is believed that the Fermi velocity value in the superconducting graphene may differ from that in the pristine graphene. With the help the Blonder-Tinkham-Klapwijk formalism, the conductivity $G$ is calculated taking into account the fact that the external potential $U$ is applied to the superconducting part of the given structure. The coefficients of both the normal and the Andreev reflection are evaluated within the framework of the Dirac-Bogoliubov-de Gennes equations. It is shown that the determining factor in the formation of the conductivity is the process of the Andreev reflection. A characteristic feature of the $G(E)$ dependence is the presence of a peak at the energy point which depends on the value of the rotational angle. The value of the maximum (peak) value of $G(E)$, as well as the $G(E)$ curve steepness essentially 
depends on the value of the Fermi velocity $v_{F}$. The dependence of the conductivity on the potential $U$ as well as on the Fermi level $E_{F}$ is analyzed for different values of the rotational angle. The obtained results may be useful for applications in the graphene-based electronics

\section{References}

1. Geim A., Novoselov K. The rise of graphene. Nature Materials. 2007. No. 6. P.183-191. 2. Castro Neto A., Guinea F., Peres N., Novoselov K., Geim A. The electronic properties of graphene. Rev. Mod. Phys. 2009. No. 81. P. 109-162.

3. Lei Liuab, Yu-Xian Li, Jian-Jun Liu Transport properties of Dirac electrons in graphene based double velocity-barrier structures in electric and magnetic. Physics Letters A. 2012. Vol. 376. No. 45. P. 3342-3350.

4. Wanga Y., Liub Y., Wang B. Resonant tunneling and enhanced Goos-Hänchen shift in a graphene double velocity barrier structure. Physica E. Vol. 53. 2013. P. 186-192.

5. Sun L., Fang C., Liang T. Novel Transport Properties in Monolayer Graphene with Velocity Modulation. Chin. Phys. Lett. 2013. Vol. 30. No. 4. P. 047201-1-047201-4.

6. Arnaud R., Marco P., Reza A., Hamilton A., Rosario F., MacDonald A. Velocity-modulation control of electron-wave propagation in graphene. Phys. Rev. B. 2010. Vol. 81. P. 073407-1-073407-4.

7. Concha A., Tešanović Z. Effect of a velocity barrier on the ballistic transport of Dirac fermions. Phys. Rev. B. 2010. Vol. 82. P. 033413-1-073407-4.

8. Yuan. J., Zhang. J., Zeng. Q., Zhang J., Cheng Z. Tunneling of Dirac fermions in graphene through a velocity barrier with modulated by magnetic fields. Physica B: Condensed Matter.. 2011. Volume 406, Issue 22. 15 November 2011. P. 4214-4220.

9. Krstajic P., Vasilopoulos P. Ballistic transport through graphene nanostructures of velocity and potential barriers. Journal of Physics Condensed Matter. 2011. Vol. 23. 135302 (8 pp).

10. Korol A., Medvid N., Litvynchuk S. Transport Properties of the Dirac-Weyl Electrons Through the Graphene-Based Superlattice Modulated by the Fermi Velocity Barriers. Springer Proceedings in Physics. 2015. Vol. 167. P. 215-221.

11. Korol A., Sokolenko A., Sokolenko I. The energy spectra of the graphene-based quasiperiodic superlattice. Low Temperature Physics. 2018. Vol. 44, No. 8, P.803-809.

12. Blonder G., Tinkham M., Klapwijk T. Transition from metallic to tunneling regimes in superconducting microconstrictions: Excess current, charge imbalance, and supercurrent conversion. Phys. Rev. B. 1982. Vol. 25, P. $4515-4532$.

13. Goudarzi H., Sedghi H., Khezelrou M. Mabhouti K., Tunneling conductance in gappedgraphene-based normal metal-insulator-superconductor junctions: case of massive Dirac electron. Physica C: Superconductivity. 2010. Vol. 470, No. 22. P. 1981-1985.

14. Bhattacharjee S., Sengupta K. Tunneling Conductance of Graphene NIS Junctions. Phys. Rev. Lett. 2006. PRL 97, P. 217001-1-217001-4.

15. Korol A., Litvynchuk S., Medvid N., Isai V. The Effect of the Fermi Velocity on the Conductivity of the Graphene-Superconductive Graphene Junction. Nanophysics, Nanomaterials, Interface Studies, and Applications: Selected Proceedings of the 4th International Conference Nanotechnology and Nanomaterials (NANO), August 24-27. 2016. Lviv, Ukraine. P. 383-393.

16. Goudarzi H., Khezelrou M. Tunneling conductance in a gapped graphene-based normal metal-insulator-d-wave superconductor junction: Case of massive Dirac electrons Physica. 2010. Vol. 43, No. 2. P. $604-609$.

17. Linder J., Sudbo A. Dirac-fermions and conductance-oscillations in (s,d)-wave superconductor/normal graphene junctions. Phys. Rev. Lett. 2007. PRL 99. P.147001-1-147001-4. 